\title{
Moebius strip enterprises and expertise in the creative industries: new challenges for lifelong learning?
}

\section{To be published in the International Journal of Lifelong}

\section{Education, Spring 2007}

\begin{abstract}
The paper argues that the emergence of a new mode of production - co-configuration is generating new modes of expertise that EU policies for lifelong learning are not designed to support professionals to develop. It maintains that this change can be seen most clearly when we analyse Small and Medium Size (SMEs) enterprises in the creative industries. Drawing on concepts from Political Economy - 'Moebius strip enterprise/expertise' and Cultural Historical Activity Theory - project-object' and the 'space of reasons', the paper highlights conceptually and through a case study of an SME in the creative industries what is distinctive about the new modes of expertise, before moving on to reconceptualise expertise and learning and to consider the implications of this reconceptualisation for EU policies for lifelong learning. The paper concludes that the new challenge for LLL is to support the development of new forms expertise that are difficult to credentialise, yet, are central to the wider European goal of realising a knowledge economy.
\end{abstract}

Co-configuration, Moebius strip expertise, project-object, Activity Theory 


\section{Introduction}

The idea that economic development is education-led has been the conventional wisdom in educational policy and research for well over a decade (Griffiths and Guile 2004). This issue has been addressed in Europe by emphasising education in its re-designated form as lifelong learning as a major policy that facilitates economic competitiveness, the development of knowledge and skill throughout the life course, social cohesion and individual fulfillment (EC 2000; 2001). Initially, policies for lifelong learning were concerned to extend access to 'formal learning' which leads to a diploma or certificate in an organised and structured context, educational or workplace) (Green 2002: 172). This focus has been supplemented over the last few years as policymakers have recognised the importance of offering validation for 'informal' (i.e. learning arising from daily life activities arising from work, family or leisure) and non-formal' learning (i.e. learning embedded in planned activities that are not explicitly designated as learning, but which contain an important learning element). The main idea behind the identification, assessment and recognition of these forms of learning has been to support employability in the European knowledge economy by making 'visible the entire scope of knowledge and experience held by an individual' (Colardyn and Bjornavöld 2004: 69). It has

resulted in a number of measures in many European couuntries to validatie these forms of learning within mainstream educational programmes and qualifications (Colardyn and Bjornavöld 2004: 69).

Paradoxically, despite the emphasis on supporting change in working life through making learning visible, EU policies are predicated on very traditional assumptions about knowledge, learning and expertise (Griffiths and Guile 2004: 71-3). Domains of 
knowledge are conceived as though they are homogeneous and separated from one another; expertise is conveived of as individual mastery of the knowledge associated with a domain and/or the skills gained by practice in the presence of experts (the famous novice-master continuum) and learning is viewed as processing, filtering and retrieving information. Taken together, these assumptions result in a very instrumental view of the relation between knowledge, learning and expertise in EU policies. Formal learning is predicated on the filling out of blanks or knowledge gaps, informal and non-formal learning are predicated on offering validation for knowledge and skill acquired experientially and expertise is conceived as the accumulation of qualifications.

The problems associated with assumptions about expertise and learning has recently been highlighted by Yrjö Engeström (2004). He has argued that the emergence of a new mode of production - 'co-configuration', that is, the development of new products and services based on the integration of company, customer and supplier, is generating a new type of expertise - 'knotworking' which calls for the capability to collaborate with each of the above parties. Engeström maintains that it is difficult to develop this type of expertise whilst the above assumptions about learning and expertise hold sway in lifelong learning policies. This paper accepts the broad thrust of Engeström's argument about the link between the emergence of new modes of production and new modes of expertise, however, it argues that his ideas about knotworking reflect only one expression of this development. This is because the Finnish public and private sectors which Engeström has typically researched - health and finance have stable 'objects of activity', that is, the product or service that they are attempting to realise, though they are under pressure to re-configure them in new ways. 
This paper argues that other economic sectors such as the 'creative industries' (Howkins $2002)^{i}$ which consist of a mix of global corporations and a large number of small and medium size companies (SMEs), are also closely involved with co-configured production yet are characterised by a rather different mode of expertise. Unlike the health and finance sectors, which in addition to a consistent object of activity are usually characterised, according to Engeström, by a clear division of labour and fairly stable level of funding etc, the situation is not as clear-cut for many SMEs in the creative industries. SMEs can only remain in business if they secure commissions for their services, and this requires strategic and operational flexibility.

The paper elaborates and extends two concepts - Moebius strip enterprise and Moebius strip expertise, which originally surfaced in the debates about the implications of PostFordism for the organisation of work to encapsulate the way in which many SMEs in the creative industries work to fulfil commissions. These concepts convey through the image of a looped ribbon twisted once, on the one hand, that SMEs are able to turn themselves to serve different purposes according to the needs of commissions they are tendering for, rather than to operate with a given modus operandi. On the other hand, that SMEs are able to co-configure their expertise to suit each commission, rather than operate with a given application of expertise. Both features are essential if SMEs are to secure commissions for work through a process of competitive tendering and establish their professional reputation in order to secure further contracts.

This paper argues that the concept of Moebius strip expertise and the form of learning required to develop it are very different from the way in which expertise and learning are viewed in European lifelong learning policy and also by Engeström. The paper develops 
this argument by first summarising Engeström's analysis of the link between new modes of expertise, new modes of production and their implications for learning. It then briefly outlines what is distinctive about the creative industries and the nature of the working and learning challenges SMEs face in those industries. The paper then moves on to elucidate its use of the concepts of Moebius strip enterprise and expertise conceptually and through a case study based on the work of an SME operating in the creative industries. Finally, the paper concludes by arguing that the emergence of Moebius strip expertise calls for broader definitions of learning in European lifelong learning policies so facilitating prospective development not just the acquisition of qualifications.

\section{New modes of production and expertise}

In a series of studies, Engeström and his colleagues have identified the emergence of a new form of organizing and performing expert work activity which they refer to as ‘negotiated knotworking’ (Engeström, Engeström \& Kärkkäinen, 1995; Engeström, Brown, Christopher \& Gregory, 1997; Hasu \& Engeström, 2000). Knots, acording to Engeström (2004: 153) are:

'rapidly pulsating, distributed and partially improvised orchestration of collaborative performance between otherwise loosely connected actors and activity systems as they tie, untie and retie together otherwise separate threads of activity'.

Knots are very different therefore from teams or project groups which have a fixed membership for a specific period of time; knots form as members of interacting multiple teams in organisations such as banks, hospitals or law courts come together for very short periods of time to resolve particular problems. Moreover, unlike teams where the question of leadership and membership is usually agreed in advance, the locus of 
initiative changes from moment to moment within a knotworking sequence as members of interacting multiple teams and their clients engage in inter-professional collaboration (Engeström 2004: 153). Hence from Engeström's activity-theoretical perspective, the life of a knot is too short for it to develop a relatively stable object, motive, community, and division of labour, and, for this reason, is unlikely that a systemic infrastructure (i..e an activity system) will evolve and stabilize. Knots, for (Engeström 2004: 155), best thought of as:

'bundles of tightly interconnected actions performed collectively by individual members of the knot in such away that agency and initiative keep shifting....Knotworking differs from an action, therefore, in that the 'subject is not fixed - the subject is the pulsating knot itself, or in other words, subjectivity is dynamically distributed within the knot'.

Engeström (2004: 154) points out that while examples of knotworking may be found in well-established practices, the rise and proliferation of this type of work 


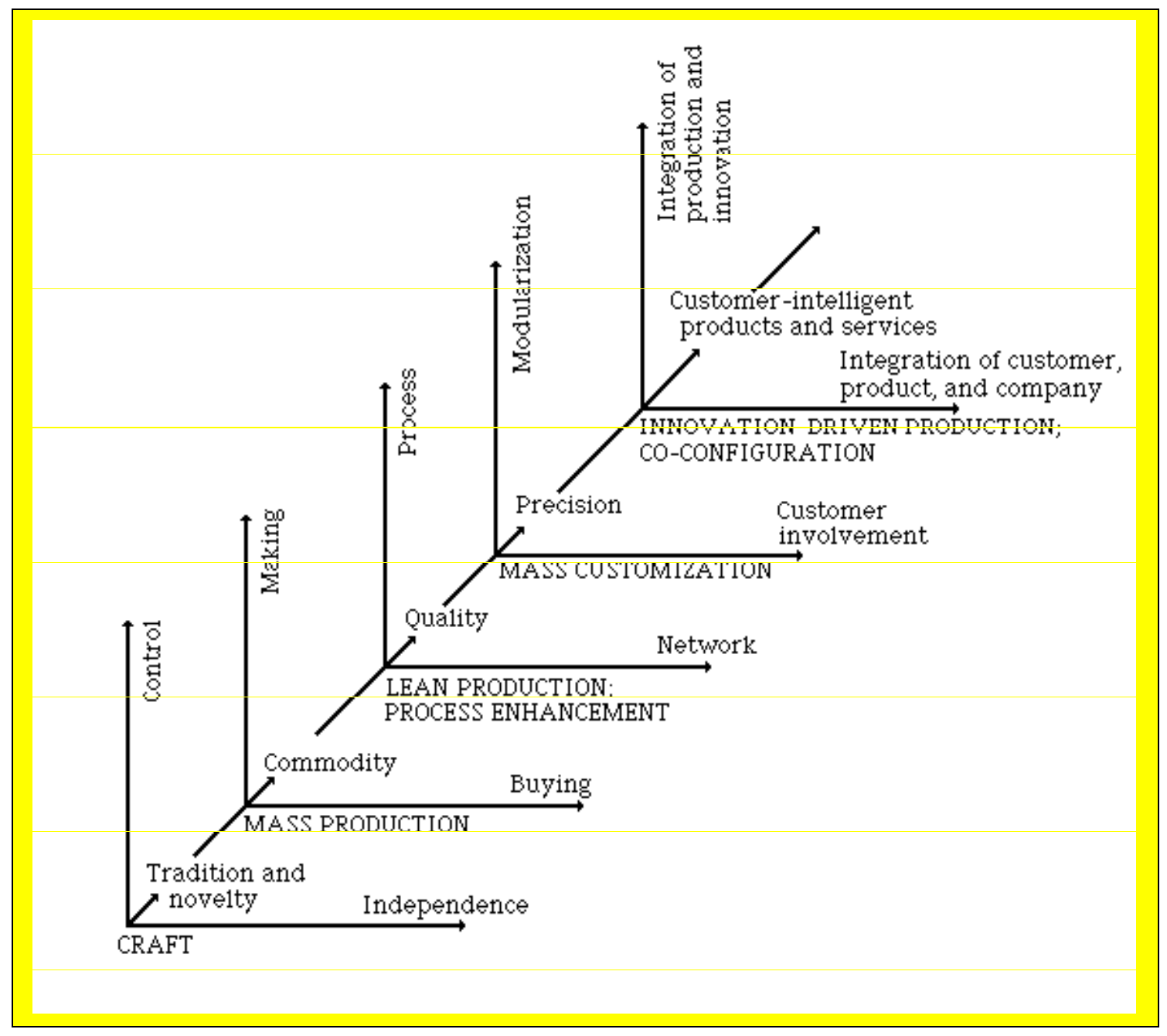

Figure 1. Typology of work (Engeström 1999, based on Victor \& Boynton 1998)

is primarily associated with the emergence of a new mode of production - 'coconfiguration. He borrows this term from Victor and Boynton (1998) who have conceptualised the principles of production from craft, via Fordism and neo-Fordism (i.e. mass production and process enhancement) to Post-Fordism (i.e. mass customization, and co-configuration. The last one of the five, co-configuration which Victor and Boynton (1998: 140) define as 'requiring constant interaction among the firm, customer, and product' is central to knotworking. A hallmark of co-configuration is 'customer intelligence'. To achieve it, a company has to continuously configure its products and services in interaction with the customer. This presupposes a new context for work based 
on the 'interdependency between multiple producers forming a strategic alliance, supplier network, or other such pattern of partnership which collaboratively puts together a complex product or service' (Engeström 2004: 155). This extension of those who contribute to the process of production not only increases the complexity of interactions in co-configuration work, but also results in knotworking becoming the emerging interactional core of co-configuration.

One of the major challenges for firms engaged in co-configuration is to generate the expertise required for this type of work. Historically, the generation of new modes of expertise has often proved problematic for firms. This is partly because most organisational models of training and development were predicated on filling out knowledge or skill gaps, rather than fostering the development of new ways of working and new forms of expertise (Guile and Fonda 1999). It is also partly because many organisational change strategies such as 'T-sets' and 'action learning' were designed to develop senior management thinking about existing practice, rather than to foster interprofessional collaboration to generate new practice (Engeström et al. 1996).

One way to assist firms to overcome these problems and to develop the collaborative and transformative expertise entailed by knotworking is, according to Engeström (2004: 152) to use his Developmental Work Research Methodology (DWRM). The DWRM provides, in theory, a framework to assist interacting multiple teams who are distributed over several sites to identify and to resolve the contradictions in work practices which are inhibiting knotworking and impeding the development of this new form of expertise. To accomplish this goal, it is necessary, according to Engeström (2004: 154) to establish a special space a 'boundary crossing laboratory' where participants can use his 
methodology the 'expansive learning cycle' to engage in a specific type of learning action. These actions are designed to lead them to question accepted practice, to gradually expand their actions into a collective movement that results in the generation of a new concept which can be used to guide the future organisation of work, to implement the new work design and, in the process, to generate collaborative and transformative expertise.

The DWRM is an innovative research methodology which enables researchers to step out of their traditional role as analysts and observers and to work alongside professionals to generate new modes of expertise in individual or small clusters of workplaces ${ }^{\mathrm{ii}}$. The DWRM presupposes, however, a specific theoretical and methodological approach thus it is difficult to see how the DWRM could be replicated more widely within the economy as a strategy to develop expertise. Nevertheless, despite expressing these reservations about Engeström's proposed solution to the problem of the development of new modes of expertise, his argument about the link between new modes of production, new modes of expertise and new modes of learning is still valid. The implication of this insight is now pursued through an analysis of SMEs in the creative industries.

\section{Creativity, the Creative Industries and SMEs}

Creativity has been a topic for discussion in Art History and the Psychology of Art since the publication of Koestler's The Act of Creation in the early sixties, specifically in relation to formal experimentation in fields of artistic activity in what has traditionally been deemed to be 'high art', for example, art, classical music, theatre etc. This more pluralistic conception of creativity has, however, emerged in recent years. This can be attributed to a number of developments. The first is the series of studies by writers such 
as Boden (1990), Csikszentmihalyi (1994; 1996) and Gardner (1993), Kaufman and Baer (2005) and Sternberg (1999) which have explored the multidimensional and mutually reinforcing forms of creativity beyond its original association with high art. These writers have considerably broadened the definition of creativity by demonstrating the scope that exists for people to be creative in fields of human activity such as science, technology, management and design.

The second is the process of industrial convergence which has gradually established the conditions for cultural, economic and technological activity to be intertwined in radically new ways (Coffee 1996). The paradigmatic example of this type of convergence is found in what is called the 'creative economy'. Some writers, for example, John Howkins (2002) define the creative economy in terms of the outputs achieved by the following fifteen industries: Crafts, Design, Fashion, Film, Music, Performing Arts, Publishing, Research and Development, Software, Toys, TV and Radio and Video Games. While other writers, for example, Richard Florida focus on the occupations that generate the new ideas that enable those industrial segments to flourish ${ }^{\mathrm{iii}}$. Irrespective of which view of the creative economy is adopted, it is widely accepted that the common link between both definitions of that economy is that it rests on 'creativity, skill and talent which have a potential for wealth and job creation' (DCMS 2001:5).

One of the hallmarks of the creative industries is that they straddle what has traditionally been referred to as 'high' and 'popular' art and the spaces in between these dominant conceptions of cultural production. The relationship between these three fields of cultural production was clarified by Bourdieu (1993) some time ago by distinguishing between the field of 'restricted production', 'large-scale production' and 'social art'. The first term 
refers to those fields where the stakes of competition between artists largely involve the accumulation of symbolic capital through experimentation with artistic forms, that is, securing prestige and the consecration of artistic reputation and celebrity within national Academies. The middle term refers to cultural forms where the dominant concern is to appeal to the largest possible audience to maximise the 'bottom line', for example, Hollywood. While the final term designates the space that exists between restricted and large-scale production for art that fulfils a social or political function, for example, 'agitprop' art.

From Bourdieu's perspective, the 'space for creative works' is considerably greater in the field of restricted production than either of the other two fields (Johnson 1993: 17). Bourdieu bases this claim on a series of interlinked arguments. He maintains that the field of restrictive production is characterised by 'two economic logics': the 'anti-economy of pure art' and the 'economic logic of the literary and artistic industries' (Bourdieu 1996: 142). This creates a tension between artists who disavow economic profit and the industries that promote their work which do not. One consequence of the anti-economy of pure art is that it provides a creative space where artists can position themselves to experiment with the forms of pure art as opposed to satisfying the exigencies of the market. Hence the hierarchy of their authority in their respective field is based on the accumulation of forms of 'symbolic profit, that is, the profit one has on seeing oneself (or being seen) as one who is not searching for profit' while the symbolic capital they acrue from this artistic stance is consecretated in and sustained by a vast social apparatus encompassing museums, galleries, libraries and so forth (Johnson 1993: 15). In contrast, the space for creative work is significantly diminished, according to Bourdieu, for artists in the field of large-scale production or social art because there is no equivalent in these 
fields of the anti-economy of pure art so the unfettered market economic logic dominates, with the result that the former seeks to maximise its audience rather than experimenting with artistic forms and the latter produce forms of art that compromises between aesthetic and material considerations.

Bourdieu's analysis of the cultural field was undertaken before the emergence of new industries such as video and IT, the re-classification of film, television and so forth as the creative industries and also before the re-thinking of the concept of creativity. These developments have led to a considerable reappraisal of cultural production. Instead of following Bourdieu and assuming that the boundaries between the different fields are economically and aesthetically insulated from one another; many writers contest his claim that the anti-economy of pure art applies any longer in the field of restricted production and draw attention to the increasing permeability of cultural forms and their relation to one another (Frow 1995: 39) ${ }^{\mathrm{iv}}$. One consequence of this development that is relevant to the focus of this article is that the accumulation of symbolic capital is now seen as a central concern in all fields of cultural production (Frith 1996). What is distinctively different about this new conception of symbolic capital compared with Bourdieu's original definition is that it is based on the explicit intertwining of aethetic and economic consideraration: symbolic capital is accrued because products and services are deemed to be innovative or have mass appeal.

Another hallmark of the creative industries is that the profile of the clusters and sectors that comprise those industries are rather different from the historical profile of conventional economic sectors such as the automobile and pharmaceutical industries (Florida 2002). The latter industries have usually been characterised by a vibrant 
corporate sector that had strong 'strategies', 'structures', 'systems' which facilitated the manufacture of standardized products and services, even though they have been subject to considerable change over the last decade (Bartlett and Ghoshal 1997). In contrast, the profile and structure of the creative industries are charactertised by value chains and networks that are constantly being formed between the corporates and SMEs, often coming together for only the lifetime of a product or service (Florida 2002).

What is distinctive about many SMEs in segments of the creative economy such as art and design, media production etc is that their workforce tend to prize entrepreneurial autonomy and creative choice, transactional freedom and artistic responsibility as the basis for the generation of their expertise and professional vision, over the institutionalisation of expertise that occurs once professionals work inside large corporations (Florida 2002: 67-70). Unlike most corporations who build their professional reputation on the basis of a particular 'house-style' or recognisable pattern of working or service delivery (Ghosal and Wensey 1993), many SMEs in the creative industries choose to realise their the entrepreneurial and creative preferences by keeping an open mind about business opportunities. Consequently, they tend to askew, unlike SMEs who operate in supply chains in other industrial sectors such as manufacturing, investing in functionally-specific technologies and fixed production systems which tie them into long term relationships with as part of multinationals' supply chains (Unwin et $a l$. forthcoming). These relationships can often place severe restrictions on the scope for innovation in work processes and for opportunities for learning amongst the workforce. Realising the aforementioned entrepreneurial and creative preferences presupposes an open-ended and socio-spatial and temporally distributed form of work, with the result that SMEs' creative activity can be stretched over a mutlitude of sites, organisations and 
alliances. The implications of this way of working for SMEs' expertise is explored in the next section.

\section{Moebius strip enterprises and Moebius strip expertise}

The changes in work organisation depicted in Victor and Boynton's typology have been debated in Political Economy and Organsational Science for over two decades in terms of the extent to which Fordist methods of production and organisational forms have been superceded by Post-Fordist modes of production and work organisation (Benyon and Nichols: 2006) ${ }^{\mathrm{v}}$. In an attempt to offer greater clarity as regards the different expressions of Post-Fordism, Charles Sabel applied the term Moebius strip enterprise to identify what he felt was distinctive about some of new organisational structures emerging in response to turbulent market conditions of the late 1980s. The gist of Sabel's (1991: 25) argument was that in an attempt to avoid the Fordist tendency to standardise operating procedures and thereby limiting their ability to respond swiftly to changing market conditions, some organisations positioned themselves to customise their product range by introducing:

'risk distribution strategies that blurred hierarchical distinctions in firms, the boundaries between them, and the boundary between firms in a particular area and the public and private institutions of the local society [he called such production structures: DG] Moebius strip organisations because they were designed to be easily redesigned'.

Furthermore, Sabel acknowledged that this new form of organisation had implications for existing conceptions of expertise. Whereas under Fordism labour market required workers to acquire specific skill-sets, Moebius strip enterprises presupposed that workers developed the 'ability to cooperate in particular settings..... to cross company lines' rather than base their expertise on 'traditional connections to particular materials and 
processes' (Sabel 1991: 25). The new form of expertise associated with Moebious strip enterprises was, referred to by Sabel (1991: 25), as 'Groucho Marx identities', that is, a disposition to accept a much more more ambivalent relationship in the labour market.

Given that Sabel's concept of Moebius strip enterprise focused on the relation between new modes of production and new modes of expertise in SMEs in the creative industries, it provides a useful starting point for conceptualising the link between SMEs' entrepreneurial and expertise challenges. Its focus on the traditional organisational concern for strategies, systems and structures means, however, that is less helpful in capturing the relation between SME's method of working and their creative activity. For this reason, I have elaborated and extended the concept of Moebius strip enterprise in a number of ways.

The first way is by linking it to the concept of the object of activity to make visible the way in which SMEs' collaborations with stakeholders can result in new products and services. The concept of the object of activity in Cultural Historical Activity Theory has always denoted two notions: the realisation of a new product or service and the idea of making the world a better place, possibly linked as a motive to the object of creating new products and services ${ }^{\mathrm{vi}}$. I have used the first sense of the term as a way to identify Moebius strip enterprises' freedom to identify which commisisons they will tender for. Furthermore, when I talk about SMEs constructing their object of activity to create new products and services I follow Nardi (2005: 39) and distinguish between the 'formulation' of an object, that is, figuring out what it should be, and the 'instantiation' of an object, that is, the work that goes into realising an object to achieve a particular outcome. 
Now at first sight, the idea that SMEs create products and services that have not existed previously seems to imply that their object of activity is literally formulated and instantiated afresh in relation to each new commission. This is not quite the case. There is a sense in which this happens because commissions' goals vary enormously and their end points are open and susceptible to ongoing revision as forms of expertise, often not imagined in advance of commencing the commission. Consequently, SMEs are able to enrich and change the object during the production process. Nevertheless, there is also a sense in which products and services are subordinate to the wider context of the industry in which they are located and whose continuities help to give meaning to their work and reputation beyond the 'transient actions' associated with a particular commission (Hyyaslo 2002: 22). For this reason, it is helpful to conceive of Moebius strip enterprises as formulating and instantiating, what Hyssalo (2005: 31) refers to as, 'project-objects' ${ }^{\text {vii }}$ in order to capture the idea that acts of creativity occur in a context which offers some continuity to that creativity.

The second way in which the original meaning of Sabel's concept has been elaborated and extended is by identifying the form of expertise required to formulate and instantiate a project-object, rather than following Sabel and concentrating on the disposition required to work in flexible labour markets. This allows me to highlight the way in which traditional aspects of the creative process, for example, the use of the imagination to formulate innovative designs are enhanced and transformed in co-constructed modes of production.

The first type of expertise that is needed to realise a project-object is, as Miettinen has 
highlighted (2005: 60), the epistemic expertise required to build various kinds of material entities, skills, and social functions into the object in such a way that 'they are aligned and coordinated so as to make the new object functionally coherent and representative of all parties' desires and interests'. This dimension of expertise requires careful coordination. This is partly because the knowledge professionals acquire though their initial professional formation, as Jensen and Lahn (2005: 308) reveal, serves to 'bind' them to their profession. It generates, in other words, a 'wanting structure', that is, a desire to fill out the blanks to 'make the picture whole and complete' (ibid), with the result that professionals can become rather insular and primarily concerned with the continued unfolding of their own expertise, rather than being receptive to the ideas and experiences of other professionals. Thus, it follows that one of the hallmarks of inter-professional collaboration is a desire to engage with the heterogeneity of knowledge that is required to realise project-objects.

The second type is the pedagogic expertise to assist all stakeholders to operate in the 'space of reasons' (Guile forthcoming), that is, the normative context which makes knowledge possible. The space of reasons introduces a very different sense of the purpose of communication compared with much of the conventional wisdom about interprofessional communication. Most writers acknowledge the inter-subjective basis of communication and maintain that professionals working in multi-specialist or multiinterest teams build their understanding dialogically and materially as they share 'mental models' (Nonaka and Takeuchi 1995) or 'representations' (Star and Greisemer 1989) with one another. This conception of communication rests on the 'representational paradigm' (Brandom 2000; 45), that is, the idea that communication occurs as we assimilate other people's ideas and beliefs about the world. This approach to inter- 
professional communication tends to gloss that sharing a mental model or a representation presupposes not only grasping its propositional basis, but also being able to infer what does or does not follow from those propositions.

This is not a straightforward matter because models and/or representations are rarely transparent. In some situations, they are mediated by the theoretical concepts and presuppositions that are part and parcel of the special and distinctive domain of professional competence (Goodwin 1994: 29). In other situations, they are mediated by professionals combining disparate phenomena, including dialogue, artefacts and inscriptions, to analyse problems and draw inferences from that analysis to communicate with colleagues from different domains of professional expertise (Hall et al. 2003: 204). While in other situations they are mediated invisibly by the ubiquitous classification systems (ways of segmenting things) and their associated standards (procedures for how to do things) that are embedded in 'working infrastructures' that constitute the context for professional activity (Bowker and Star 2000:147).

In contrast, the space of reasons introduces the idea that it is only when as we begin to understand the system of mediating connections between other professionals' concepts, judgements and practices that we are able to communicate effectively with them (Guile forthcoming). Thus deleted The concept replaces the emphasis in the representational paradigm on the assimilation of mental models with the idea that the purpose of communication is to support us to infer what follows from someone's utterance, symbolic representation or actions. Thus it follows that as professionals begin to understand other professional's system of mediating connections between their concepts, judgements and practices, they are gradually repositioned in relation to one another's expertise. 
Professionals start to develop a fuller sense of the potential of the project-object, with the result that they start to see how to incorporate ideas and practices that are a part of another professional community so as to instantiate the object. Furthermore, it also follows that one of the main pedagogic challenges of con-configuration is for professionals and professional communities to make the rationale for their models, representations and practices explicit. It is the creation of these knowledge cultures, rather than the acquisition of knowledge, which enables all parties engaged in collaborative activity can grasp the system of mediating connections and infer what does or does not follow from such judgements and assessments.

Making the meaning of mental models and representations transparent is far less problematic in stable professional communities where longstanding enculturation practices induct newcomers to professional traditions (Lave and Wenger 1991) and in large-scale organisations where knowledge or 'epistemic cultures' foster interprofessional collaboration (Knorr Cetina 1999). The issue of transparency and interprofessional communication is, however, much more problematic in large swathes of the creative industries. First, SMEs' creative activity is often streteched over a mutlitude of sites, organisations and alliances who have only come together for the life of a project; hence their context of work is bereft of the enculturation practices and work cultures that help to make transparent the meaning of mental models and representations. Second, the emergence of co-configured modes of production leaves many professionals working in SMEs with an acute dilemma. They require 'object-focused support', that is, in situ deleted mentoring and coaching to help them to develop the epistemic and pedagogic expertise to formulate and instantiate project-objects, yet, they often lack the financial or human resources to assist them to develop such forms of expertise (Guile forthcoming). 
Unfortunately, this situation is compounded by the lack of support available to SMEs through EU policies for lifelong learning. The primary focus of EU policies is on the extension of access to formal learning or the validitation of informal and non-formal learning that has already been accrued. Such policies are wholly inadequate as strategies to develop the aforementioned epistmeic and participatory expertise. The former perpetuates the notion that the development of expertise consists of the plugging of knowledge gaps, while the latter represents a strategy to validate retrospectively knowledge and skill acquired experientially. Although both are worthy measures in the terms in which they were originally conceived, neither are geared to supporting the development of Moebius strip expertise. As a consequence, SMEs are forced to develop such expertise though a process of trial and error and, in the process, run the risk that they may fail and go out of business or through concincing intermediary agencies who administer European funds to adopt a broader strategy as regards the deployment of such funds. The following case study of an SME in the creative industries illustrates these two strategies ${ }^{\text {viii }}$.

\section{Formulating and instantiating project-objects: a case study of Renn \& Thacker}

The Renn \& Thacker Partnership has existed in Birmingham since 1994. Like most SMEs in the field of public arts, Renn \& Thacker have to win and be judged to have successfully fulfilled commissions otherwise they will go out of business. There are two main domains of activity where Renn \& Thacker look to secure commissions: sculpture in bronze, steel, copper, fibre-optics, terracotta, film and video; and, arts project planning, management and consultancy services. These two domains are not necessarily separate, frequently they can be combined within the same commission. 
The unifying link between the two type of commmissions is the idea of focusing on the site itself rather than a particular medium or process and given application of expertise. As Renn \& Thacker (http://renn\&thacker.com) remark:

'With this approach and through collaboration, we strive to expand the limits of possibility. You could say that we specialize in not specializing'.

Successfully securing commissions in either domains involves Renn \& Thacker, on some occassions, taking the lead in formulating and instantiating with partners and stakeholders a proposal to meet the requirements of a commission and, on other occassions, responding to an invitation to contribute their expertise and participate in a tender which another SME has won. To turn their expertise to reflect the needs of a specific tender, Renn \& Thacker have applied and refined a site-specific strategy for realising new project-objects over the last decade. What is novel about this approach is that the partnership has learnt through their own efforts, and at the risk of going out of business if they had been un-successful, to extend a traditional aesthetic strategy for designing features for specific physical spaces in relation to situations and scenarios that call for the notion of 'site' into the non-physical. Thus, they are a paradagmatic example of a Moebius strip enterprise: they instantiate and realise new project-objects collaboratively with other stakeholders and, in the process, hope to further consecrate their reputation in the creative industries.

Case Study 1. Clink Sculpture, Stourbridge

Clink is sited at the new pedestrian bridge link across Brook Road, Stourbridge, Wiltshire 
and forms a gateway to the recently opened 'Park and Ride' at Stourbridge Rail Station. This sculpture celebrates the world famous glass industry in Stourbridge which dates back to the $17^{\text {th }}$ century. The sculpture comprises of two champagne flutes, which meet to form a triangular entry feature for the footbridge, is a celebration of local pride. The artwork is in the form of a toast - a toast in this instance to, Stourbridge crystal, to Clink and public transport. The sculpture is circa $7 \mathrm{~m}$ in height with each of the two towers being $1.5 \mathrm{~m}$ in diameter at their widest point. It was fabricated from stainless steel, glass cullet and toughened glass so as to create a lighting fizz at the core of the work during the hours of darkness.

Renn \& Thacker won the commission for Clink in open competition with other SMEs after formulating a provisional proposal and approximate technical specifications. The initial design was refined through a dialogue between Centro, the Project Manager, Halcro and Mark Worral Associates, the civil engineers and architects for the scheme, and Wrekin Construction. This extended dialogue enlarged space of reasons and led the different contributors to gradually deepen their collective understanding of the projectobject by considering how to reconcile competing aspirations. In the process, the contributors developed a more comprehensive understanding of how to use their collective knowledge and skill to enhance Clink's symbolic possibilities and the social functions it was supposed to achieve. Once a final design had been evolved, Renn \& Thacker held a series of meetings with the design team whereby they jointly assessed the technical implications of citing Clink on the chosen site as well as the implications of that citing in relation to the surrounding landscape. The intention of these meetings was to consider how the environmental effect could reinforce the message about local pride, sense of place and so forth which it was envisioned that Clink would symbolise. 
Renn \& Thacker also engaged in research and advocacy with Red House, Glass Cone Museum, Broadfield House Glass Musuem and Tudor Crystal Ltd., all based in Stourbridge to simultaneously get a better sense of stakeholder expectations for the sculpture and to develop support for their proposal. This research/advocacy constituted in efect, the consultation process with the local community. It resulted in some small revision of proposals in response to a variety of advice and technical and Health and Safety considerations. These revisions reflected the tension between Renn \& Thacker's desire to create an artistically and technically innovative sculpture, and their sensitivity to stakeholders' desire for a sculpture which would give the local community:

a sense of ownership, that is, a way to create through local historic context a sense of pride and achievement in the local economy;

a landmark, that is, the creation of a sense of place, announcing the arrival and departure to and from Stourbridge;

a a gateway, that is, to provide a key link in helping establish the new park and ride with a legible and safe route for pedestrians;

an awareness, that is, to raise the awareness of public transport facilities through art.

Throughout the process, Renn \& Thacker liaised continually with another SME, Form Fabrications who specialise in the field of industrial fabrication, to discuss the implications of fabricating a sculpture that consisted of stainless steel, glass cullet and toughened glass. The process of fabrication was not straightforward because most fabrication firms specialise in industrial rather than 'one-off' art fabrications. Both parties had to consider the way in which Form Fabrications could customise their normal work 
processes to fabricate Clink in accordance with its technical specifications and in time to ensure that Renn \& Thacker meet the deadline set by the Project Managers, and with minimum disruption to Form Fabrications normal work process.

Insert Picture 1 about here

Case Study 2. VIRTUAL: A web-based gallery site

VIRTUAL was launched by the Renn \& Thacker Partnership in conjunction with Arts \& Business, West Midlands and Birmingham Interaction in September 2003. The prototype for VIRTUAL having originally been developed by Experian in the East Midlands in 2001, where it ran for a trial year. The inspiration behind VIRTUAL was Renn \& Thacker's desire to help artists to move from a 'grant' culture, that is, relying primarily on grants from government agencies and charitable bodies to fund their work, towards a 'business commission' culture, that is, developing their capability to secure commissions from business. Historically, art schools have either spurned the idea of or struggled to support artists to present their work to the business community. This has left artists doubly disadvantaged: they have lacked knowledge of the demand in the business world for art and design; and, even when they steal time from their own artistic activities, they lacked the networks to develop this knowledge.

Unlike the funding for Clink which was gained through a competitive tendering process, the funding for VIRTUAL came from Renn \& Thacker 'pitching' their idea to Birmingham City Council's Economic Regeneration Department (ERD). Participation in public arts networks in Birmingham had led Renn \& Thacker to discover that the ERD 
had secured funding from the European Social Fund (ESF) for a European research and development project - 'Knowledge Support for Businesses' (KSB). The aim of KSB was to test out and identify new models of support for SMEs in the creative industries to stimulate high growth and, in the process, to create employment opportunities. Given that most artists are, in effect, small businesses, Renn \& Thacker felt that their ideas for a web-based gallery clearly fell within the remit of KSB.

In order to advance $\operatorname{VIRTUAL}$, Renn \& Thacker formed a partnership with Arts \& Business, West Midlands, an SME with a remit to forge closer links between those two different communities. Joint discussions between the SMEs enabled both parties to enlargen the space of reason in which they were collectively operating. A wider range of perspectives were brought to bear on how to reconfigure the intranet and to select and support the local artists invited to present their work for possible inclusion in VIRTUAL. In the case of the former, rather than starting to design an internet from scratch, Renn $\&$ Thacker re-rented the software from another SME, Dotin, who had been commissioned to create a much smaller, web-based gallery scheme in the East Midlands. Once permissions had been granted, Arts \& Business used their extensive links with the the West Midlands' business community to 'sign-up' organisations in the private and public sectors who were prepared to make the new web-based gallery available to their staff.

In the case of the latter, Renn $\&$ Thacker and Arts \& Business drew on their respective knowledge of the arts and business world to: determine the member of the panel of experts to select the artists whose work would be displayed on VIRTUAL; and, ensure that the workshop programme provided a space of reasons whereby representatives from the private sector, arts professionals, and successful artists could pass on ideas to the 
selected artists as regards how to target the business community to present their art to that audience in order to secure commissions and sales. Whilst participating in these sessions, Renn \& Thacker and Arts \& Business realised it was necessary to build another feature in to the programme of support. Participants were assigned experienced artists to act as mentors to assist to produce a statement and description of their work to convey its significance more succinctly to the business community, and to boost their confidence as regards presenting themselves and their work at exhibitions and other types of public events.

The final step was to work collaboratively with the ERD and other stakeholders to organise a series of promotional events to publicise VIRTUAL throughout the corporate world in the West Midlands. The dissemination of VIRTUAL which simultaneously is a resource to promote artists to the business community and to secure commmissions for artists from that community, resulted in the West Midland Arts Council providing funding for $2005 / 6$ to enable Renn \& Thacker and Arts \& Business to work with a new cohort of artists.

Insert Picture 2 about here.

\section{Moebius strip expertise and the challenge for lifelong learning}

The preceding discussion of Moebius strip enterprises and expertise has elaborated and extended the link between the emergence of new modes of production, new conceptions of expertise and new modes of learning. Specifically, it has highlighted the twofold nature of the entrepreneurial challenge such enterprises face: to secure a range of commissions and to co-configure their expertise to realise the goals of those commission. 
This has meant in Renn \& Thacker's case: on the one hand, formulating innovative designs and working with stakeholders to enlargen the space of reasons so that the final design of the project-object was informed by all parties ideas and expertise. On the other hand, identifying opportunities to extend the basis of their epistemic and participatory expertise and, in the process, supporting the developent of the next generation of SMEs.

These ways of working are critical to the success of not only Renn \& Thacker, but also many other SMEs in the creative economy because they are simultaneously concerned with 'here and now' and 'future-oriented' issues. In the case of the former, they are involved in working collaboratively with stakeholders to make decisions about the design and delivery of new products or services. In the case of the latter, the outcomes of those decisions will be judged in two senses: the body overseeing a commission will asses how far the new product or service has met or even exceeded its expectations; and, the creative industry will determine the extent to which the new product and/or service consecrates or diminishes an SMEs' symbolic capital. Moreover, both assessments will have a significant bearing on whether SMEs attract future commissions or secure further tenders.

Given the widespread acceptance in EU policies (EU 2000a and b) of the central role that SMEs in will play in the European knowledge economy and the growing awareness that SMEs lack the human and financial resources to realise this role on thir own, it is vital that SMEs in the creative industries are supported to develop the forms of expertise identified in this paper. Unfortunately, the official definitions of formal, informal and non-formal learning are not helpful in this regard. They focus as Colardyn and Bjornavöld (2004: 71) note, firmly on: 
the intention to learn and the structure in which learning takes place. The intention to learn explains the centrality of the learner in the learning process and the structure refers to the context (i.e. school, workplace, community: DG) in which learning takes place.

Despite their progressivism in broadening what counts as learning so as a greater range of knowleldge and skill can be credentialised (Colardyn and Bjornavöld 2004: 69), the definitions of formal, informal and non-formal learning direct our attention towards sites where something called 'learning' happens or the organisation of something called 'learning', without ever shedding any light on what such learning might consist of. Thus, they perpetuate the idea that expertise consists of the accumulation of qualifications rather than the development of human capability to act and intervene in economic, social, cultural and political affairs in new and novel ways. One reason for this concern for the intention and structure of learning is, as Billett (2003: 118) has observed, that policymakers have unproblematically taken 'concepts and assumptions associated with formal learning as premises for what constitutes the formalisms and structure of legitimate learning experiences'. With the result, as Billett has also observed (ibid), that they have described informal and non-formal learning by what it is not, rather than attempting to illuminate its qualities or characteristics.

In the past it made sense to focus on the intention and structure of learning because learning was predominantly concerned with symbolising rites of passage, for example, the end of compulsory schooling, the acquisition of a degree and gaining a licence to practice in a professional or vocational field. It is still sensible to retain this concern for the intention and structure of learning in an era of lifelong learning since ia focus on intention and structure not only support the credentialising of a range of knowledge and 
skill that has historically been invisible, but also facilitate progression for those sections of the population who lack qualifications. Where this concern is unhelpful, however, is with regard to the qualitative shift that has occurred in the learning demands on individuals and workplaces. The emergence of new modes of production, as the preceding discussion of Moebius strip enteprises and expertise has highlighted, is generating new learning needs - learning to formulate and instantiate project-objects in heterogeneous teams. Such needs are not captured, let alone supported, in anyway at all by EU definitions of formal, non-formal and informal learning.

What is required, therefore, is a much broader conception of learning and expertise than is found currently in European policies for lifelong learning. The cornerstone of such a conception is, as the paper has argued, to recognise the multifaceted and varied mediated relation that we have with the world. This allow us to highlight the different sources of meditation, for example, material tools (i.e. intranets), a semiotic tools (i.e. concepts) or other human being, and the different contributions that they make to the development of epistemic and participatory expertise. One of the attractions of this mediated conception of development and learning is that it accords a role for a number of issues which have animated the argument about learning and expertise presented in this paper, for example, specialist and lay knowledge, object-focused creativity and innovation and individual and collective activity.

Based on the above argument, the first step to broaden EU policies for lifelong learning is to conceive of expertise as the capability to formulate and instantiate a project-object collaboratively, rather than conceiving of it as the acquisition of domain-specific knowledge and skill or as participation in knots. The distinction between formulating 
and instantiating a project-object is helpful in a number of ways. First, it is consistent with the pluralistic definition of expertise discussed earlier. Thus, it retains a traditional psychological focus on the contribution of knowledge and imagination to creativity, without limiting them to the the realm of a few selected individuals, geniuses, talented people, who produce great works of art, or who are responsible for major scientific discoveries or invent technological advances. Second, it supplements more recent definitions of expertise that have acknowledged the binding role of knowledge in professional formation, with the idea that expertise also presuposes a desire to engage with the heterogeneity of knowledge that other parties hold. In doing so, the distinction between formulating and instantiating a project-object reminds us that creativity can only become an integral part of everyday work practice when professionals remain open to one another's insights and ideas.

The second step is to conceive of learning as the location of thought, action and artefacts in the space of reasons, rather than as mastering discrete blocks of knowledge and skill or validating knowledge and skill acquired experientially. This allows us to broaden our understanding of learning in a number of ways. The first way is to concentrate on the purpose of learning as much as on the site of and organisation of learning. This constitutes a significant shift in focus. It allows us to differentiate between supporting learners to engage with existing concepts and practices, to evolve concepts and practices and to transform concepts and practices (Guile forthcoming). It is only when we can distinguish between these different purposes of learning that we are able to identify the forms of pedagogic support to help individuals and communities to accomplish these goals, for example, access to schools, colleges and universities, the provision of mentors and coaches to work alongside individuals and communities. The second way is to 
concentrate on the relationships we make through learning as much as the acquisition and internalisation of information. This also constitutes a significant shift in focus. It requires policymakers to formulate learning goals to support people to make the social basis of their thought transparent as much as goals to measure wht they have learnt. The advantage of this suggestion is that it alerts us to the value of assisting others to appreciate why we recommend a certain course of action, why that may involve the introduction of ideas, practices and artefacts from another context and why it might even involve the creation of a new context.

It thus follows from the preceeding argument that if European policies for lifelong learning are to be broadened, a greater balance has to be struck between:

$\checkmark$ the accumulation of qualifications and the development of epistemic and participatory expertise;

- the site and organisation of learning and the purpose of learning;

access to learning and the development of learning relationships.

\section{Conclusion}

This paper has made a number of inter-related arguments. The first argument is that neither cognitive nor Engeströmian conceptions of learning and expertise reflect the forms of expertise required in large swathes of the creative industries or provide the modes of learning to develop such expertise. The second argument is that EU policies for 
lifelong learning are characterised by very narrow definitions of learning and expertise, with the result that the purpose of learning and the relationship between individual and collective learning are never addressed. The third argument is that the identification of hitherto unacknowledged forms of expertise and learning needs in the creative industries problematises existing conceptions of learning and expertise in EU policies. Taken in combination, the paper concludes that the above arguments presuppose that a greater balance should be struck in lifelong learning policies between their current preoccupation with the accreditation of learning and the development of forms of expertise that may prove to be difficult to credentialise, yet, which are central to the wider European goal of realising a knowledge economy.

The argument and the conclusions drawn in this paper may seem controversial to many policymakers and researchers for a number of reasons. The former are likely to express genuine concern that unless funding for learning is tied to the accumulation of qualifications, it will be difficult to assess the 'return on the investment'. The latter may feel that one case study hardly constitutes the basis to establish a new conception of expertise and learning. In both cases, I would draw their attention to the messages emerging from some of work-based and professional learning projects funded under the UK's ESRC/TLRP's Teaching and Learning Research Programme (Daniels and Edwards; Kent et al. Unwin et al.) and Norway's ProLearn Project (Jensen and Lahn 2007). These projects are gradually amassing considerable evidence of the diversity of conceptions of expertise associated with mass customisation and co-configured production and of the diversity of workplace learning needs in these contexts which are not consistent with the prevailing definitions of learning and expertise in EU policies. 
This emerging evidence suggests that the argument presented in the paper about the link between new modes of production, new conceptions of expertise and new modes of learning is indicative of a broader trend, rather than evidence of what might at first sight be deemed to be an esoteric development. Furthermore, it also suggests that the call for broader definitions of expertise and learning to assist SMEs and other organisations to realise the aim of a European knowledge economy is a pressing concern, rather than a frivolous attempt to undermine European policies for lifelong learning.

\section{Acknowledgements}

An earlier version of this paper was presented at: the $4^{\text {th }}$ Researching Learning and Work conference which was held at the University of Technology, Sydney, December 2005, and, at the Oxford Centre for Sociocultural and Activity Research, June, 2006. I would like to thank all the members of the RWL panel session, especially Harry Daniels, and Anne Edwards and her colleagues for their very constructive comments. I would also like to express my gratitude to Michael Young for his very helpful comments as regards the organisation of the argument and structure of the paper. It goes without saying that I am entirely responsible for any errors. 
${ }^{\mathrm{i}}$ At the present time, there is an abundance of competing and contending concepts to encapsulate what is distinctive about the changes whih have occurred in national and in the global economy, for example, the 'knowledge econony', the 'informationalional economy', the creative economy'. The common link between each of these concepts is that knowledge, information and ideas - terms whose meaning, let along relationship to one another, is not always specified clearly, is now the critical economic resource. For the sake of consistency in this article, I have used the term creative economy as though it is a sub-set of the broader argument about the role of knowledge and creativity in advancd industrial economies.

ii To see how the DWRM has been used to facilitate inter-agency learning see Daniels and Edwards (ref).

iii There is general agreement that this industry is now worth worldwide about \$2,2 trillion and, according to the World Bank's estimation, is growing at 5\% per year. The largest market is America which is now worth in excess of \$1 trillion while Britain is ranked third in the creative economy behind Japan, with a market size of $£ 98$ billion (DCMS .

iv There is insufficient space in this paper to do justice to the extensive debate in Cultural Studies about Bourdieu's analysis of cultural production, a good starting point is Frow (1995).

${ }^{v}$ There is insufficient space in this paper to do full justice to the complexity of this debate, for fuller discusions please see Beynon, (2006) Piore and Sabel (1986) and Wood (1989).

${ }^{\mathrm{vi}}$ Readers who are want to explore recent debates about the concept of the object of activity are advised to consult the Special Edition of Mind Culture and Activity devoted to the object of activity (MCA 2005).

vii In activity-theoretical terms, the way in which they realise their commisisons falls between an activity and an action. For a fuller discussion of the concept of projct-object see Hyyaslo (2005).

viii The following case study is taken from a small-scale research project 'Knowledge Support for Small Businesses' funded through the EU ESF Programme and led by Birmingham City Council's Economic and Social Regeneration Department. The aim of the project was to identify the challenges that SMEs in the creative industries face as they attempt to diversify their businesses to secure an increased market share. Three overriding questions were identified as central to project and influenced its research design. What forms of knowledge do SMEs require to operate in the creative industries? How can they best be supported to develop these forms of knowledge? What are the implications of this development for economic regeneration and lifelong learning policies? Four companies were followed over the course of two years. In order to probe their views and experiences, two approaches were adopted: a narrative approach and a focus-group approach. The former consisted of interviews with representatives of the four SMEs with the researcher while the latter consisted of meetings between the SMEs and the researcher. For a fuller description of the methodology see Guile (forthcoming(b)).

\section{References}

Amin, A., (1994) Post Fordism, (London: Routledge).

Beynon, H., and Nichols, T., (2006) Patterns of Work in the Post-Fordist Era (Cheltenham: Edward Elgar)

Boden, M., (1990), The Creative Mind: Myths and Mechanims (New York: Basic Books).

Bourdieu, P., (1993), The Field of Cultural Production (London: Polity Press).

Bourdieu, P. (1996), The Rules of Art (London: Polity Press).

Bowker, G.C. and Star, S. L., (1999), Sorting things out: classifications and its consequences (Cambridge: Cambridge University Press).

Brandom, R., (2000), Articulating Reasons (Cambridge: Harvard University Press)

Coffe, D., (1996), Competing in the Age of Digital Convergence (San Franscisco: Jossey Bass)

Colardyn, D. and Bjornavöld, J., (2004) Validation of Formal, Non-Formal and Informal Learning: policy and practices in EU member States. European Journal of Education 39, 69-89. 
(New York: Harper Collins).

Daniels, H. (forthcoming) Learning in and for interschool working to promote creativity.

Engeström, Y., Brown, K. Christopher, C. \& Gregory, J., (1997). Coordination, cooperation and communication in courts: Expansive transitions in legal work. In M. Cole, Y. Engeström \& O. Vasquez (eds.), Mind, Culture and Activity: Seminal Papers from the Laboratory of Comparative Human Cognition. (Cambridge: Cambridge University Press), pp 369-389.

Engeström, Y., Engeström, R. \& Kärkkäinen, M., (1995). Polycontextuality and boundary crossing in expert cognition: Learning and problem solving in complex work activities. Learning and Instruction, 5, pp 319-336.

Ericsson, K. A. \& Smith, J. (1991). Prospects and limits of the empirical study of expertise: An introduction. In K. A. Ericsson \& J. Smith (Eds.), Toward a general theory of expertise: Prospects and limits.( Cambridge: Cambridge University Press).

European Commission (2000a), Memorandium on Lifelong Learning (Brussells: EU).

European Commission (2000b), Comunique Making Lifelong Learning a Reality (Brussells: EU).

Florida, R., (2002), The Rise of the Creative Class (New York: Basic Books).

Frow, J., (1995), Cultural Studies \& Cultural Values, (Oxford: Oxford University Press).

Engeström, Y., (2004) The New Generation of Expertise: Seven Thesis. In (eds) Rainbird, H., Fuller, A., and Munro, A., Workplace Learning in Context, (London: Routledge) pp .

Engeström, Y., Virkkunen, J., Helle, M., Pihlaja, J. and Poikela, R., (1996) 'Change laboratory as a tool for transforming work', Lifelong Learning in Europe. 1, 10-17.

Frith, S. (1996), Performance Rites (Oxford: Oxford University Press)

Gardner, H. (1993 ), Creating Minds: an anatomy of creativity seen through the lives of Freud, Einstein, Picasso, Stravinsky, Eliot, Graham, and Gandhi (New York: Basic Books).

Godwin, C. (1993), Professional Vision American Anthropologist. American Anthropologist, 96, pp 606-636.

Green, A. (2002), The many faces of lifelong learning: recent education policy trends in Europe Journal of Educational Policy. 17, pp 611-626.

Griffiths, T. and Guile, D., (2004), Learning through Work Experience, (Brussells: CEDEFOP).

Ghosal, S. and Wensey, D.E., (1993), Organisational Theory and Multinationmal Corporations, (New York: St Martin's Press).

Guile, D. (2006), The Learning Challenge of the Knowledge Economy, (Amsterdam: Sense).

Guile, D. and Fonda, N., (1999), Managing Learning for Added Value. (London: Chartered Institute for Personnel and Development (CIPD). 
Jensen, K. and Lahn, L., (2005), The binding role of knowledge: an analysis of nursing students' knowledge ties. Journal of Education and Work, 18, 3 pp 305-320.

Howkins, J. (2001), The Creative Economy ( London: Penguin).

Hyssalo, S. (2005), Objects and Motives in a Product Design Process. Mind, Culture and Activity, 12, pp 19-38.

Hasu, M. \& Engeström, Y., (2000), Measurement in action: An activity-theoretical perspective on producer-user interaction. International Journal of Human-Computer Studies, 53, pp 61-89.

Kent, P., Noss, R., Guile, D., Hoyles, C. and Bakker, A. (2007) Characterising the use of Mathemetical Knowledge in Boundary Crossing Situations at Work, Mind, Culture and Activity 11 pp233-51

Lave, J. and Wenger, E. (1991), Situated Learning (Cambridge: Cambridge University Press)

Kaptelinin, V., (2005), The Object of Activity: Making Sense of the Sense-Maker. Mind, Culture and Activity, 12, pp 4-19.

Kaufman, J. and Baer J., (2005) (eds) Creativity Across Domains, (Mahwah, N.J.: Lawrence Earlbaum).

Mathews, J. ( 1989), Tools for Change (London: Pluto Press).

Miettinen, R., (2005), Object of Activity and Individual Motivation. Mind, Culture and Activity, 12, pp 52-76.

Nonaka, I. and Takeuchi, H., (1995), The Knowledge Creating Company, (Oxford: Oxford University Press).

Piore, M. Sabel, C., (1987), The Second Industrial Divide, (New York: Basic Books).

Sabel, C., (1991), Moebius-strip Organisations and Open Labour Markets: Some Consequences of the Reintegration of Conception and Execution in a Volatile Economy. In James Coleman and Pierre Bourdieu, eds., Social Theory for a Changing Society (Boulder: Westview Press, 1991), pp. 23-63;

Star, S.L. and Greismer, R., (1989), Institutional Ecology, 'Translations' and Boundary Objects: Amateurs and Professionals in Berkeley's Museum of vetebrate Zoology. Social Studies of Science, 19, pp 387-420.

Sternberg, R., (1999), Handboook of Creativity (Cambridge. Cambridge University Press).

Unwin, L., Felstead, A., Fuller, A., Lee, T., Butler, P. and Ashton, D. (2007 in press) Worlds within worlds: the relationship between context and pedagogy in the workplace, in Nijhof, W.J. and Nieuwenhuis, L.F.M. (eds) The Learning Potential of the Workplace, Rotterdam: Sense Publishers.

Victor, B. \& Boynton, A. C. (1998). Invented here: Maximizing your organization's internal growth and profitability. (Boston: Harvard Business School Press).

Wood, S., (1989), The End of Work, (London: McMillan). 


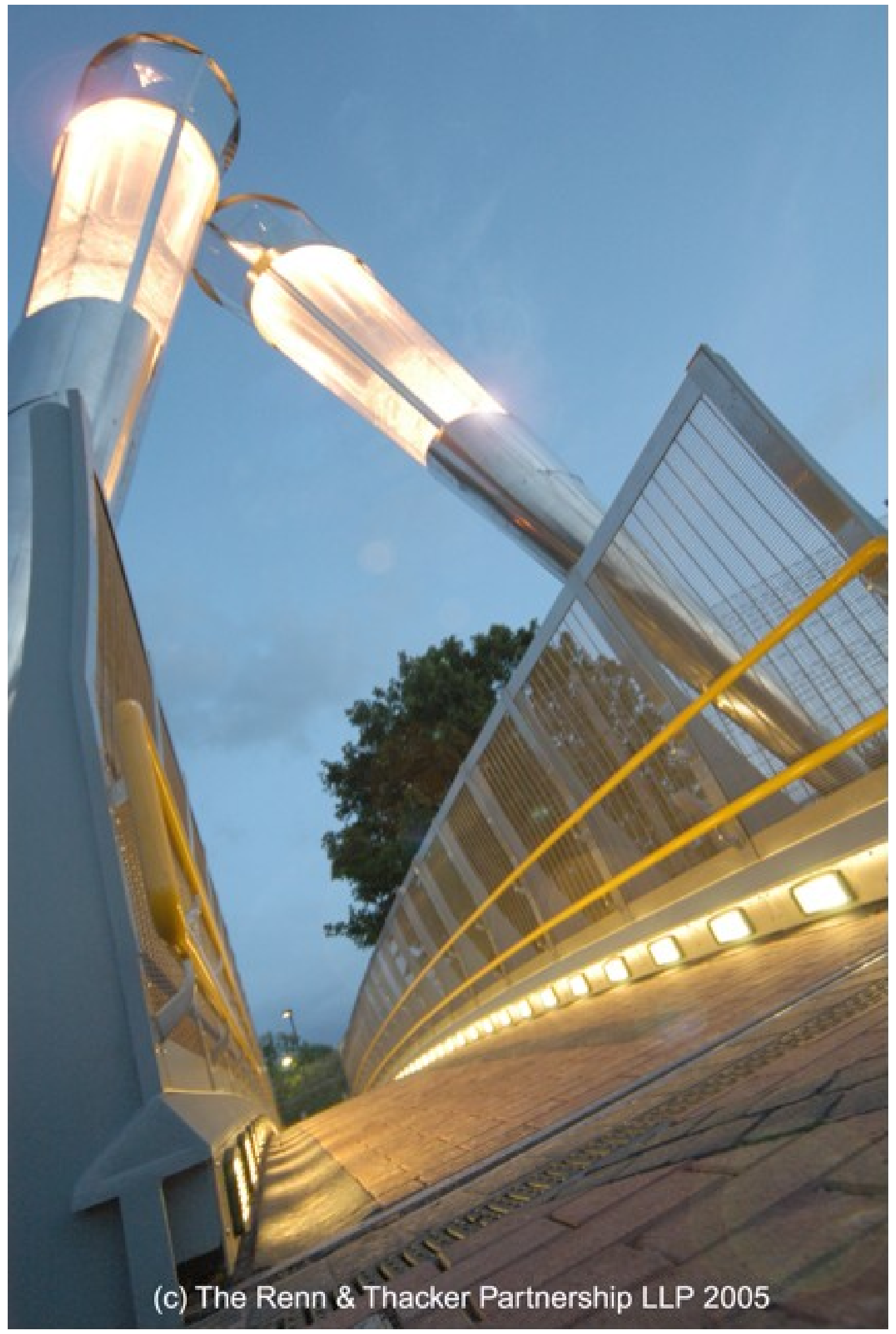


File Edit View Favorites Tools Hitp

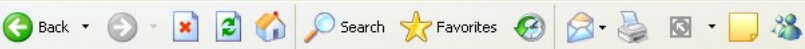

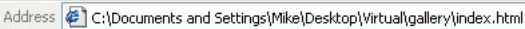

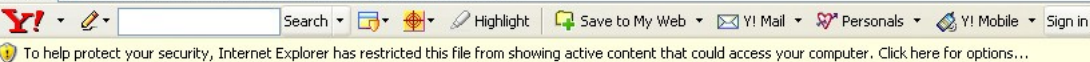

$\rightarrow$ Go Links ” Norton Internet Security $\oplus$

\section{VIRTUAL}

the gallery on your desktop

Home | The Galleries | How to Buy | About the Project | Jargon Buster | Terms and Conditions

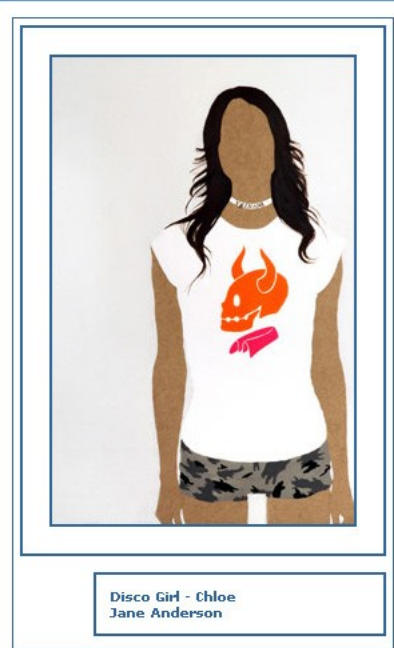

\section{Welcome to}

VIRTUAL - The gallery on your desktop

What is Virtual? workplace.

Virtual seeks to increase understanding of contemporary art and to facilitate the process of buying original works of art and using art and design services. From

How is the work selected

A panel of relevant arts professionals and business leaders select each art form. Examples of work by the selected artists and makers are also displayed at

Can I meet the artists?

Yrtist's availability and at their discretion.

Virtual is based on an original idea by the Renn \& Thacker Partnership LLP and is produced by Arts \& Business in collaboration with Renn \& Thacker, with support

from the European Social Fund.

\section{A\&B

Home | The Galleries | How to Buy | About the Project | Jargon Buster | Terms \& Conditions

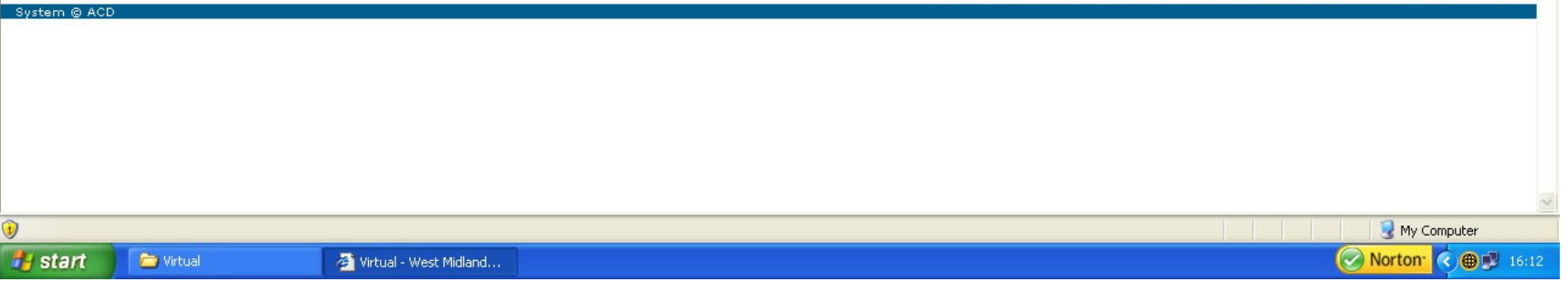

